\title{
The Conjoined Parascapular and Latissimus Dorsi Free Flap for Reconstruction of Extensive Knee Defects
}

\author{
Amir K. Bigdeli ${ }^{1}$, MD; Benjamin Thomas ${ }^{1}$, MD; Volker J. Schmidt ${ }^{1}$, MD; Dimitra \\ Kotsougiani $^{1}$, Frederick J. Hernekamp ${ }^{1}$, MD; Christoph Hirche ${ }^{1}$, MD; Ulrich Kneser ${ }^{1}$, \\ MD; Emre Gazyakan', MD
}

${ }^{1}$ Department of Hand, Plastic and Reconstructive Surgery, Burn Center, BG Trauma Center Ludwigshafen, Hand and Plastic Surgery, University of Heidelberg, Germany

\section{Corresponding author:}

Emre Gazyakan, MD, MSc

Department of Hand, Plastic and Reconstructive Surgery, Burn Center, BG Trauma Center Ludwigshafen, University of Heidelberg

Ludwig-Guttmann-Strasse 13

67071 Ludwigshafen

Germany

Tel: 0049-621 6810-2328

Fax: 0049-0621 6810-211

Email: Emre.Gazyakan@bgu-ludwigshafen.de

This is the author manuscript accepted for publication and has undergone full peer review but has not been through the copyediting, typesetting, pagination and proofreading process, which may lead to differences between this version and the Version of Record. Please cite this article as doi: $10.1002 /$ micr.30361

This article is protected by copyright. All rights reserved. 
Conflicts of interest: None of the authors received any funds or has any financial interests to disclose.

Running title: Conjoined Parascapular Latissimus Dorsi Flap

\title{
The Conjoined Parascapular and Latissimus Dorsi Free Flap for Reconstruction of Extensive Knee Defects
}

\begin{abstract}
Background: Extensive soft-tissue defects affecting the knee region pose a significant reconstructive challenge and may require separate or multiple flaps for coverage. We evaluated the conjoined parascapular and latissimus dorsi free flap as an alternative reconstructive option.

Methods: From January 2013 to December 2016, 15 patients (7 female, 8 male) with a mean age of 47.5 years underwent reconstruction of such defects. Causes were trauma (12 cases) and infection (3 cases). The mean defect size was $40.9 \times 20.8 \mathrm{~cm}$ (range, $21.4 \times 7.3-$ $60.1 \times 40.5 \mathrm{~cm}$ ). The mean defect surface area was $820.0 \mathrm{~cm}^{2}$ (range, $273.2-2400.4 \mathrm{~cm}^{2}$ ). The conjoined free flap was anastomosed to the femoral vessels in the adductor canal with (3 cases) or without an arterio-venous loop (8 cases), posterior tibial vessels (3 cases), or anterior tibial vessels (one case).
\end{abstract}

Results: Postoperatively, 10 patients experienced a total of 14 complications, of which 9 (7 patients) were considered major (requiring additional surgery) and 5 (4 patients) minor 
(conservative treatment). There was no total flap loss. Partial flap loss occurred in 5 patients. Major donor-site complications occurred in 6 patients with impaired wound healing (4 cases), seroma (one case), and hematoma (one case). Reconstruction was successful in 14 out of 15 patients during a mean follow-up time of 28.6 months (range, 6.0 to 52.5 months). Twelve patients were able to walk at the last follow-up visit.

Conclusions: The conjoined parascapular and latissimus dorsi free flap is a large and reliable flap. It allows for simultaneous one-stage reconstruction of complex and unusually large softtissue defects of the knee region.

Key words: Conjoined free flap, knee defect, knee reconstruction, latissimus dorsi, parascapular 


\section{Introduction}

As a result of technical advancements and increasing microsurgical experience, free flap transfer has evolved to a routine procedure in reconstructive surgery. Nevertheless, extensive soft-tissue defects of the lower limb including the knee region continue to pose a significant challenge to the plastic surgeon, especially when the complete circumference of the limb is affected. Additionally, the wide zone of injury generally precludes the use of local flaps. Microvascular defect reconstruction with separate flaps is possible, but can be challenging, time consuming, and exhaustive. The alternative to multiple individual flaps is a conjoined flap, which may allow for one-stage defect reconstruction. Here, the subscapular system offers the greatest variety of independent flaps, which are all linked together by a common source vessel. ${ }^{1}$ Due to its various components, conjoined flaps from the subscapular vascular system are an excellent choice for one-stage reconstruction of extensive, complex, and threedimensional defects. ${ }^{1}$ Nassif and colleagues were the first to demonstrate the feasibility of a conjoined parascapular and latissimus dorsi muscle free flap in cadaver models. ${ }^{2}$ Former studies have demonstrated high flap reliability, but only little is known about complication rate, donor-site morbidity, patient satisfaction, as well as long-term results. ${ }^{3-9}$ We present our experience with the conjoined fasciocutaneous parascapular and latissimus dorsi muscle free flap for reconstruction of extensive soft-tissue defects affecting the lower leg and knee region. The indication for its application, the incidence of complications and their management as well as reconstructive long-term results are discussed.

\section{Patients and Methods}


After approval of the local ethics committee (Mainz, Germany), all medical records of patients undergoing free tissue transfer for lower extremity reconstruction from January 2013 to December 2016 were identified in the free flap database of our center. The protocol of this study was in accordance with the Declaration of Helsinki. Fifteen patients (7 female, 8 male) with a mean age of 47.5 years (range, 29 to 68 years) underwent microvascular reconstruction of extensive soft-tissue defects of the lower limb using the conjoined parascapular and latissimus dorsi free flap. The indications were extensive soft-tissue defects of the lower limb and knee region, usually wider than their length. The defects resulted from radical debridement of compromised soft-tissue after high-energy trauma (12 cases) or extensive infection (3 cases). The mean defect size was $40.9 \times 20.8 \mathrm{~cm}$ (range, $21.4 \times 7.3$ to $60.1 \times 40.5$ $\mathrm{cm}$ ). The mean defect surface area was $820.0 \mathrm{~cm}^{2}$ (range, 273.2 to $2400.4 \mathrm{~cm}^{2}$ ). Six defects included the complete circumference of the knee and lower leg and nine defects were semicircular. A detailed summary of the patient`s characteristics is given in the Table. Nine patients underwent simultaneous treatment of fractures or bone defects, in detail plate osteosynthesis of the femur (2 cases) and tibia shaft (4 cases), total knee replacement (2 cases), and arthrodesis of the knee joint (one case). In the majority of cases, we performed end-to-side anastomoses to the femoral artery in the adductor canal, or end-to-side anastomoses to the anterior or posterior tibial artery.

\section{Surgical technique}

The anatomic scheme of the flap design is shown in Figure 1. Free flap raising was performed according to standard principles. Whenever possible, we aimed to perform all operative stages in the lateral decubitus position with the arm abducted 90 degrees on an arm rest. When this 
was not possible, the operation was performed in three subsequent stages. First, the conjoined flap was harvested and banked in the lateral position. In the second step, the patient was placed in the supine position and the accompanying osseous injuries were treated. In the third step, the recipient vessels were exposed and the microvascular anastomoses were performed. Management strategies for each complex case were meticulously planned by a multidisciplinary team of clinicians (plastic and reconstructive surgeon, trauma surgeon, vascular surgeon) in our extremity board.

Flap raising was always started with the fasciocutaneus parascapular flap. The triangular space was identified by palpation and the exit point of the circumflex scapular artery confirmed by acoustic Doppler probe. The flap was then designed by planning the axis along the descending branch of the circumflex scapular artery, confirmed by acoustic Doppler probe, from the posterior axillary line towards the midline of the back with the maximum amount of area still allowing primary donor-site closure according to the pinch test. We preferred to approach flap dissection directly to the triangular space through incision of the superior medial flap border. The circumflex scapular vessels were identified and the entrance into the flap was surrounded by including the fascia. Dissection of the circumflex scapular vessels was then extended through the triangular space towards the subscapular artery. Afterwards, the flap was raised from inferior to superior and attached to the latissimus dorsi muscle. Flap harvest was continued with the latissimus dorsi muscle. The incision was extended distally and the superficial surface of the complete muscle was exposed. The lateral muscle border was then elevated and muscle dissection was continued superiorly to expose the thoracodorsal vessels and nerve as well as the serratus arcade. The serratus arcade was divided the way to allow later microvascular in-flap anastomosis. The thoracodorsal vessels 
were then dissected to reach the subscapular system. The entire muscle was then harvested from inferiorly. After dissection of both vascular pedicles to the bifurcation of the subscapular system, the parascapular flap was pulled through the triangular space. Depending on the recipient-site, the conjoined flap was either banked in sterile dressings after partial closing of the donor-site or harvested through ligating the subscapular vessels.

In selected patients, end-to-end anastomoses via an arterio-venous loop (AVL) to the femoral vessels in the adductor canal or thigh, interposing the ipsi- or contralateral great saphenous vein, were performed. The parascapular flap was then used to cover the AVL. Furthermore, whenever possible or needed, we tried to cover bony structures with the fasciocutaneus parascapular flap in order to facilitate future surgical access in case of revisional surgery such as prosthesis implantation, implant removal or bone grafting procedures.

\section{Follow-up}

All patients were included in the retrospective analysis. Follow-up was established from the date of surgery to the last clinical visit. The incidence of complications and their management as well as reconstructive long-term results and patient satisfaction were analyzed.

\section{Results}

The mean size of the harvested latissimus dorsi muscle was $27.4 \times 18.2 \mathrm{~cm}$ (range, $17.0 \times$ 12.2 to $35.0 \times 38.3 \mathrm{~cm}$ ), and of the fasciocutaneous parascapular flap $27.7 \times 7.5 \mathrm{~cm}$ (range, $23.1 \times 6.5$ to $31.6 \times 9.0 \mathrm{~cm})$. 
In two cases, the circumflex scapular and thoracodorsal arteries did not unite and thus arose separately from the axillary artery. In these cases, a microsurgical in-flap anastomosis of the circumflex scapular artery to the serratus arcade was successfully performed prior to flap harvest.

Free flap anastomoses were performed in end-to-side technique to the femoral vessels in the adductor canal (8 cases), femoral vessels in the adductor canal or thigh via AVL (3 cases), posterior tibial artery and end-to-end anastomosis to the concomitant vein (3 cases), anterior tibial artery and end-to-end anastomosis to the concomitant vein (one case).

The mean operation time was 598 minutes (range from 310 to 879 minutes). Five patients received a mean of 2.1 erythrocyte concentrates perioperatively.

Primary donor-site closure was achieved in all but one case (14 cases). This patient required partial split-thickness skin grafting of the donor-site, because an oversized parascapular flap was intentionally harvested and the consequence accepted at that time.

The postoperative course was uneventful in five patients. However, ten patients experienced a total of fourteen complications. Complications, which required additional surgical procedures (partial flap necrosis, wound dehiscence, hematoma, seroma), were considered as major (9 cases) and occurred in seven patients. Complications, which were manageable by conservative means (partial flap necrosis, seroma), were considered minor (5 cases) and occurred in four patients. There were no postoperative vascular complications (arterial and/or venous thrombosis). Microsurgical re-exploration was only necessary in one patient due to hematoma formation from bleeding at the vascular pedicle without impairment of flap perfusion.

This article is protected by copyright. All rights reserved. 
There was no total flap loss but partial flap necrosis occurred in five patients. Three extended parascapular flaps had marginal distal necrosis, whereas two healed under conservative measures and one required debridement and split-thickness skin grafting. One latissimus dorsi flap developed minor superficial muscle necrosis and required debridement and splitthickness skin grafting. One patient, suffered from severe pyoderma gangraenosum ulceration at the donor-site as well as both flaps with partial flap loss. She underwent consecutive transfemoral amputation.

Primary wound healing of the donor-site without any complication was achieved in eight patients. Seven patients experienced donor-site complications, of which six were major complications. In detail, wound dehiscence was observed in four patients, persistent seroma in one patient, and persistent hematoma in one patient. All cases of wound dehiscence required additional surgery with successful primary wound closure alone (3 cases) or in combination with split-thickness skin grafting (one case). A large donor-site hematoma was operatively evacuated on the first postoperative day. Persistent donor-site seroma occurred in two patients, whereas one was evacuated surgically and the other treated conservatively.

The mean length of hospital stay was 70 days (range from 26 to 132 days). The mean length of hospital stay after flap surgery was 46 days (range from 14 to 95 days).

Finally, reconstruction was successful in 14 out of 15 patients during a mean follow-up time of 28.6 months (range, 6.0 to 52.5 months). All but one limb could be salvaged. Twelve patients were able to walk at the last follow-up visit, of whom two presented with a slightly limping gait pattern. As mentioned before, one patient (No. 9) underwent transfemoral amputation and was proceeding with prosthesis training. The same course underwent another patient (No. 5), as she underwent contralateral lower leg amputation during initial surgery. All 
successfully treated patients presented with stable soft-tissue conditions and stated that they would undergo the operation again. They found that the reconstructive success of lower limb salvage justified both the donor-site morbidity as well as the cosmetic outcome.

\section{Case Reports}

\section{Case 1}

A 29-year-old male sustained a comminuted femoral shaft fracture during a traffic accident. During surgery, all necrotic and avascular bone was removed and the segmental bone defect of $20 \mathrm{~cm}$ treated by intramedullary nailing and implantation of a cement spacer. In the long term the objective was to treat the bone defect with segmental bone transport. After further debridements and negative pressure therapy, an extensive soft-tissue defect $(35 \times 28 \mathrm{~cm})$ affecting the thigh and knee region with exposed femur cement spacer was present (Figure 2a). One months after the accident, the defect was successfully reconstructed through a conjoined parascapular $(30 \times 9 \mathrm{~cm})$ and latissimus dorsi $(38 \times 30 \mathrm{~cm})$ free flap (Figure 2b,c). The subscapular artery was anastomosed to the femoral artery in the adductor canal in end-toside fashion, the subscapular vein in end-to-end fashion to the femoral vein. The fasciocutaneous parascapular flap was used to cover the cement spacer in order to facilitate surgical access to the femur in the future. The latissimus dorsi flap was used to cover the knee and to obliterate the dead space of the thigh region. Split-thickness skin from the contralateral leg was grafted on the latissimus dorsi flap. Postoperatively, the conjoined flap healed uneventfully. Flap training was initiated on postoperative day seven. However, wound

This article is protected by copyright. All rights reserved. 
dehiscence of the donor-site occurred and required resurgery with split-thickness skin grafting. Wound healing proceeded without further complications.

Ten weeks after the accident, the patient was discharged from hospital with healed wound conditions and non-weight bearing crutch walking. Five months after initial surgery, the parascapular flap was raised in order to remove the cement spacer and implant an external fixator for bone transport. Bone continuity of good quality was achieved after 128 days and transport was finished. On last follow-up, bone union had progressed and combined bone grafting using autologous cancellous bone from the iliac crest and plate osteosynthesis of the femur planned (20 months after the accident and 14 months after beginning transport). The conjoined flap showed an aesthetically satisfying reconstruction (Figure 3a-c). The patient's passive knee range-of-motion was from $0^{\circ}$ extension to $55^{\circ}$ flexion without pain. Active knee range-of-motion was not possible from the beginning due to massive damage of the quadriceps femoris muscle. The patient is still put on non-weight bearing crutch walking.

\section{Case 2}

A 58-years-old male sustained an extensive decollement injury of the left leg in combination with a displaced fracture of the tibial head during a traffic accident. After multiple debridements and negative pressure therapy, an extensive soft-tissue defect $(55 \times 27 \mathrm{~cm})$ affecting the thigh, knee and lower leg with exposed tibia was present (Figure 4a). Three weeks after the accident, open reduction and plate osteosynthesis of the tibial fracture was performed. Simultaneously, the soft-tissue defect was successfully reconstructed by a conjoined parascapular $(26 \times 10 \mathrm{~cm})$ and latissimus dorsi $(34 \times 20 \mathrm{~cm})$ free flap. In order to reach the distal border of the defect with the latissimus dorsi flap, an AVL was established to 
the femoral vessels using the contralateral saphenous vein (Figure 4b). The subscapular vessels were then anastomosed to the AVL in end-to-and fashion. The parascapular flap was used to cover the AVL and the latissimus dorsi flap to cover the knee and tibia (Figure 4c,d). The latissimus dorsi flap was covered with split-thickness skin from the contralateral leg. However, partial split-thickness skin grafting of the donor-site was necessary during flap surgery, because we harvested an oversized parascapular flap and accepted the consequence at that time (Figure 5e). Postoperatively, both donor- and recipient-site healed uneventfully. Flap training was initiated seven days after flap surgery and went uneventful. The further postoperative period passed without complications. Two months after the accident, the patient was discharged with healed wound conditions and gradual weight-bearing crutch walking. Full weight bearing was allowed after 6 months. Follow-up after 14 months showed an aesthetically and functionally satisfying reconstruction (Figure 5a-d). At the last follow-up visit 14 months after flap surgery, the patient was full weight-bearing with a slightly linking gait pattern and an active knee range-of-motion of $0-10-120^{\circ}$. The patient was fully recovered and had returned to all his activities of daily living and work without restriction.

\section{Discussion}

The conjoined fasciocutaneous parascapular and latissimus dorsi muscle free flap has been used infrequently for soft-tissue reconstruction of the lower limb and head and neck region. ${ }^{3-9}$ For successful reconstruction of extensive soft-tissue defects of the lower limb that include the knee region, one must remember, that the knee is both a highly mobile area with a large surface area, as well as a collection of vulnerable and bradytroph structures (tendons, bones, 
and cartilage) in need of well perfused soft tissue coverage. Both attributes should not be underestimated and especially the knee's range of motion must be taken into account for flap choice.

When regional options are available and the wound size allows, pedicled muscle flaps are the first considered option for reconstruction of soft-tissue defects around the knee. ${ }^{10-13}$ Due to its reliable blood supply and straightforward dissection, the pedicled gastrocnemius flap is the workhorse for coverage of small to moderate defects of the upper third of the leg and knee. ${ }^{13}$ The medial gastrocnemius flap is not only larger than the lateral but also has a greater arc of rotation. ${ }^{13}$ Its size varies from 5 to $9 \mathrm{~cm}$ in width and 13 to $20 \mathrm{~cm}$ in length. It can be used to cover wounds between 3 and $7 \mathrm{~cm}$ in width and surface areas between 33 and $49 \mathrm{~cm}^{2} .{ }^{2}$,15 Size (around $5 \times 12 \mathrm{~cm}$ ) and arc of rotation of the lateral gastrocnemius flap are generally smaller. $^{10,11,13}$ It is mostly used to cover lateral knee defects. ${ }^{10,11,13}$ In summary, the gastrocnemius flap has proved as a robust option for reconstructing small to moderate knee defects with good functional results. ${ }^{10-13,15}$ However, it may be less effective for reconstruction of more complex, proximal and larger knee defects. ${ }^{10-13,15}$ The distally based pedicled gracilis flap, based on minor pedicles from the superficial femoral or popliteal artery, is an option for coverage of more proximal or lateral knee defects. ${ }^{11,16}$ However, the flap carries a high risk of partial flap loss and thus is reserved for patients in which the pedicled gastrocnemius flap is not possible or free flap coverage is contraindicated. ${ }^{16}$ The distally based vastus lateralis flap may be a potential regional solution in case of failure of the gastrocnemius flap. However, it has been less commonly used as it may be less suitable for medial knee defects. Furthermore, harvesting the flap precludes the use of the anterior lateral thigh (ALT) perforator flap due to ligation of the descending branch of the lateral femoral 
circumflex artery. ${ }^{12}$ A reliable option for covering proximal anterior or medial knee defects is the distally based ALT flap. It can be harvested up to $15 \times 32 \mathrm{~cm}$ to cover defects up to $15 \times$ $27 \mathrm{~cm} .{ }^{11,17}$ However, the increased risk of venous congestion, flap tip necrosis, and the need to perform skin grafting at the donor-site are potential disadvantages. ${ }^{11}$ Lastly, these regional options may not be applicable to the complex and extensive soft-tissue defects around the knee as present in the demonstrated cases.

Recently, Gravvanis and colleagues reviewed current concepts of flap-based reconstruction of defects around the knee and proposed an algorithm. Regarding defects larger than six centimeters, they proposed free flap reconstruction. They identified the ALT perforator flap for superficial wounds or as a chimeric flap with parts of the vastus lateralis muscle for deeper wounds as the flap of choice in the majority of cases. In the case of more extensive soft-tissue defects, they stated that free flap reconstruction is a better option, because it avoids further scaring and trauma to an already injured limb. The well-perfused tissue might also bring stability to the wound and promote healing. ${ }^{13}$

The main advantage of the conjoined parascapular and latissimus dorsi free flap is its large surface area, which makes it an excellent choice for one-stage reconstruction of extensive and complex soft-tissue defects. Furthermore, the independent mobility of its components due to the inverted Y-shape vascular pedicle enables various ways of positioning and threedimensional coverage of large and complex defects. ${ }^{5}$ Also, the latissimus dorsi muscle flap can be used to obliterate deep and hollow defects. ${ }^{5}$

Another advantage is that only one pair of vascular anastomoses is required in most cases. Sano and colleagues successfully reconstructed two massive defects around the knee with multiple-island combined flaps based on the subscapular axis. They proposed that the site of 
the anastomoses should be positioned at the level of the knee. Here, they preferred the anterior tibial vessels as recipient vessels. But since end-to-side anastomosis is difficult in this area, they distally dissected the anterior tibial artery and reversed it in order to achieve end-toend anastomosis at the knee level. ${ }^{3}$ However, we do not support this approach as it may reduce or even jeopardize the perfusion of an already traumatized limb. We agree with Gravvanis and Fang et al., that the proper selection of the recipient vessels is the main difficulty and challenge and thus essential for the success of a free tissue transfer of defects around the knee. ${ }^{18,19}$ Gravvanis et al. concluded that the recipient vessel of choice should be identified by preoperative vascular imaging. Straightforward end-to-end anastomosis to smaller vascular branches close to the defect (sural or genicular artery) is preferred. As trauma may involve superficial sited vessels as well as vessels in the area of injury, the superficial femoral vessels are the recipient vessels of choice for end-to-side anastomosis. Furthermore, they stated that the choice of the recipient vessels directs the choice of the most suitable flap. ${ }^{13}$ In our series, we started to anastomose the conjoined flap to the anterior or posterior tibial artery in an end-to-side fashion, in earlier cases usually in close proximity of the injury. Later on, we continued to establish end-to-and anastomoses via an AVL to the femoral vessels in the adductor canal or thigh interposing the ipsi- or contralateral great saphenous vein. The reasons were: (1) Paucity of recipient vessels of the lower leg; (2) Avoidance of vascular anastomosis in the area of injury; (3) Distances between anastomotic site and distal end of the defect surpassing 30 centimeters. In these cases, we used the parascapular flap to cover the AVL in order to achieve tension-less wound closure and to avoid compression of the AVL. Furthermore, we always tried to cover bony structures with or without osteosynthesis with the fasciocutaneus parascapular flap in order to facilitate future 
surgical access in case of revisional surgery, such as prosthesis implantation, implant removal or bone grafting procedures.

Further merits of the conjoined parascapular and latissimus dorsi free flap are the consistent and well-known anatomy of the subscapular vascular system and easy flap dissection. However, both the thoracodorsal and the circumflex scapular vessels can arise directly from the axillary vessels with absence of a common source vessel in up to four percent of cases according to the literature. ${ }^{20,21}$ We experienced this vascular anomaly in two patients, where the circumflex scapular artery arose directly from the axillary artery. It was managed with a microsurgical in-flap anastomosis of the circumflex scapular artery to the serratus arcade. That is why we recommend to ligate the serratus arcade at the very end of flap dissection in order to retain the option of an in-flap anastomosis.

The alternative to a conjoined flap for reconstruction of defects too large to be covered with a single flap is to transfer two free flaps with two separate pairs of anastomoses. However, it is needless to say, that this may increase the operation time as two pairs of vascular anastomoses have to be performed. It may even have to be carried out in stages, thus requiring two separate operations. Furthermore, this approach may require two different recipient vessels in case of extensive lower limb trauma with diminished vessel quality or, alternatively, a flap-to-flap anastomosis. On a final note, performing two separate free flaps may result in a considerably prolonged operation time, if not performed in a logistically demanding two-team approach for flap harvesting. It may not only be costly and economically inefficient, but also associated with a higher risk of flap failure and increased peri- and postoperative morbidity and mortality. ${ }^{22-24}$ 
One of the most important goals of modern reconstructive microsurgery is to minimize donorsite morbidity. ${ }^{25}$ In our series, primary donor-site closure was possible in all but one patient, as we intentionally harvested an oversized parascapular flap and initially accepted the consequence. With hindsight we could see it was a poor decision. One should always aim at closing the donor-site primarily without the use of skin grafts as the latter may increase donor-site morbidity significantly and lead to a poor functional and cosmetic outcome. In such a case, we would now prefer, if possible, to transfer two free flaps from different regions. Maghari and colleagues reported an elegant modification. They covered an extensive lower leg defect with an expanded $15 \mathrm{~cm}$ wide and $41 \mathrm{~cm}$ long parascapular flap $(15 \times 41 \mathrm{~cm})$ in conjunction with a latissimus dorsi free flap. Furthermore, they included a large retrograde hinge flap of the tissue expander capsule $(8 \times 11 \mathrm{~cm})$ for reconstruction, which was covered with split-thickness skin. Expansion enabled primary donor-site closure. ${ }^{26}$

However, most of the complications in our report were associated with the donor-site, in detail impaired wound healing, seroma, and hematoma. The incidence of wound complications at the donor-site was perceived lower in the later cases, which we attribute to the use of incisional negative pressure wound therapy applied upon the primarily closed incision four five to ten days after the operation. Furthermore, an elastic abdominal corset was always put on the donor-site in the operating room. It was then replaced through a custommade compression that was worn night and day for six weeks. Furthermore, it should be mentioned that we harvested larger parascapular flaps in the first cases in order to keep all options open for reconstruction. We then continued to harvest smaller parascapular flaps, which were also sufficient for successful reconstruction and - at the same time - reduced donor-site morbidity. The major advantage of the conjoined flap is indeed the flexibility of 
flap inset as well as the possibility to reach the distal defect border. However, considering the complexity of the defects to reconstruct, donor-site morbidity was acceptable. Nevertheless, the significant donor-site morbidity of the conjoined parascapular and latissimus dorsi free flap must be taken into consideration if too much tissue is taken.

Regarding the postoperative outcome, we did not experience any total flap loss. Partial flap loss occurred in five of fifteen patients. We would like to highlight, that three extended parascapular flaps (exceeding $30 \mathrm{~cm}$ in length) developed marginal distal necrosis that could have been prevented by harvesting smaller flaps. Conservative local measures alone yielded satisfactory wound healing in three patients. Two patients underwent debridement and successful split-thickness skin grafting of the necrotic areas. We also want to emphasize, that only one patient suffered a microsurgical complication, more precisely a hematoma from consecutive bleeding at the vascular pedicle without impairment of flap perfusion. We attribute this positive outcome to the great vessel diameter of the subscapular vessels and the high arterial blood flow through the flap. This may reduce the incidence of arterial and venous thrombosis. Furthermore, precise preoperative vascular as well as coagulation diagnostics are indispensable requirements. In summary, despite a high postoperative complication rate, we could expand our limits for limb salvage as reconstruction was successful in all but one patient. In extremity reconstruction, the conjoined parascapular and latissimus dorsi free flap To our knowledge, this is the largest series to date reporting microvascular reconstruction of extensive soft-tissue defects around the knee with the conjoined parascapular and latissimus dorsi free flap. Our report focuses on different aspects of microvascular and clinical decision making, such as recipient vessel selection and flap positioning, that have rarely been addressed before. However, our report is limited because of the small number of cases as well 
as it`s retrospective character. The lack of a direct comparative group (e.g. multiple flap reconstruction) and a standardized assessment tool for objective evaluation of the outcome after reconstructive surgery are further limitations.

\section{Conclusions}

The conjoined fasciocutaneous parascapular and latissimus dorsi muscle free flap is an extremely large and highly reliable flap. It allows for reconstruction of extensively wide and three-dimensional soft-tissue defects of the knee region too large to be covered with a single flap. Furthermore, direct donor-site closure can be achieved and should also be given top priority. Lastly, the conjoined flap may overcome the need for multiple conventional flaps, thereby reducing operative time, recovery intervals, related morbidity, patient mortality, and overall treatment costs.

\section{Literature}

1. Hallock GG. Permutations of combined free flaps using the subscapular system. J Reconstr Microsurg. 1997;13(1):47-54.

2. Nassif TM, Vidal L, Bovet JL, Baudet J. The parascapular flap: a new cutaneous microsurgical free flap. Plast Reconstr Surg 1982;69(4):591-600.

3. Sano K, Hallock GG, Ozeki S, Suzuki H, Mawatari R, Yoshino K, Hamazaki M. Devastating massive knee defect reconstruction using the cornucopian chimera flap from the subscapular axis: two case reports. J Reconstr Microsurg 2006;22(1):25-32. 
4. Germann G, Bickert B, Steinau HU, Wagner H, Sauerbier M. Versatility and reliability of combined flaps of the subscapular system. Plast Reconstr Surg 1999;103(5):13861399.

5. Wu WC, Chang YP, So YC, Ip WY, Lam CK, Lam JJ. The combined use of flaps based on the subscapular vascular system for limb reconstruction. Br J Plast Surg 1997;50(2):73-80.

6. Sawaizumi M, Maruyama Y, Kawaguchi N. Vertical double flap design for repair of wide defects of the lower limb, using combined ascending scapular and latissimus dorsi flaps. J Reconstr Microsurg 1995;11(6):407-414.

7. Aviv JE, Urken ML, Vickery C, Weinberg H, Buchbinder D, Biller HF. The combined latissimus dorsi-scapular free flap in head and neck reconstruction. Arch Otolaryngol Head Neck Surg 1991;117(11):1242-1250.

8. Kimata Y, Tsukada S, Iwamoto T, Harii K. Free combined parascapular flap and latissimus dorsi muscle flap for facial palsy and neck reconstruction. Br J Plast Surg 1995;48(7):515-517.

9. Karle WE, Anand SM, Clain JB, Scherl S, Buchbinder D, Smith ML, Urken ML. Use of a combined latissimus dorsi scapular free flap revascularized with vein grafting to the internal mammary artery in a vessel-depleted and previously irradiated neck. Head Neck 2013;35(11):E328-32.

10. Andres LA, Casey WJ, Clarke HD. Techniques in soft tissue coverage around the knee. Tech Knee Surg 2009;8(2):119-125.

11. Osei DA, Rebehn KA, Boyer MI. Soft-tissue Defects after Total Knee Arthroplasty: Management and Reconstruction. J Am Acad Orthop Surg 2016;24(11):769-779. 
12. Rao AJ, Kempton SJ, Erickson BJ, Levine BR, Rao VK. Soft Tissue Reconstruction and Flap Coverage for Revision Total Knee Arthroplasty. J Arthroplasty 2016;31(7):1529-1538.

13. Gravvanis A. Flap reconstruction of the knee: A review of current concepts and a proposed algorithm. World J Orthop 2014;5(5):603.

14. Veber M, Vaz G, Braye F, Carret JP, Saint-Cyr M, Rohrich RJ, Mojallal A. Anatomical Study of the Medial Gastrocnemius Muscle Flap: A Quantitative Assessment of the Arc of Rotation. Plast Reconstr Surg 2011;128(1):181-187.

15. Menderes A, Demirdover C, Yilmaz M, Vayvada H, Barutcu A. Reconstruction of soft tissue defects following total knee arthroplasty. Knee 2002;9(3):215-219.

16. Mitsala G, Varey AHR, O’Neill JK, Chapman TW, Khan U. The distally pedicled gracilis flap for salvage of complex knee wounds. Injury 2014;45(11):1776-1781.

17. Lu LJ, Gong X, Cui JL, Liu B. The anteromedial thigh fasciocutaneous flap pedicled on the supragenicular septocutaneous perforator: Application in 11 patients. Ann Plast Surg 2011;67(3):275-278.

18. Fang T, Zhang EW, Lineaweaver WC, Zhang F. Recipient vessels in the free flap reconstruction around the knee. Ann Plast Surg 2013;71(4):429-433.

19. Gravvanis A, Delikonstantinou I, Chatzigakis PK, Tsoutsos D. Femoral vessels as recipient for free tissue transfer coverage of around-the-knee defects. Microsurgery 2013;33(4):333-334.

20. Bartlett SP, May JW, Yaremchuk MJ. The latissimus dorsi muscle: a fresh cadaver study of the primary neurovascular pedicle. Plast Reconstr Surg 1981;67(5):631-636.

21. Rowsell AR, Davies DM, Eizenberg N, Ian Taylor G. The anatomy of the subscapular-

This article is protected by copyright. All rights reserved. 
thoracodorsal arterial system: study of 100 cadaver dissections. Br J Plast Surg $1984 ; 37(4): 574-576$.

22. Wong AK, Nguyen TJ, Peric M, Shahabi A, Vidar EN, Hwang BH, Niknam Leilabadi S, Chan LS, Urata MM. Analysis of risk factors associated with microvascular free flap failure using a multi-institutional database. Microsurgery 2015;35(1):6-12.

23. Cheng H, Chen BP-H, Soleas IM, Ferko NC, Cameron CG, Hinoul P. Prolonged Operative Duration Increases Risk of Surgical Site Infections: A Systematic Review. Surg Infect (Larchmt) 2017;18(6).

24. Daley BJ, Cecil W, Clarke PC, Cofer JB, Guillamondegui OD. How slow is too slow? Correlation of operative time to complications: An analysis from the tennessee surgical quality collaborative. In: Journal of the American College of Surgeons 2015;220:550558.

25. Chen HC, El-Gammal TA, Chen HH, Wei FC, Lin CH, Tang YB. Economy of donor site incisions: multiple free flaps of the subscapular family for extensive extremity wounds and bilateral foot defects. Ann Plast Surg 1998;41(1):28-35.

26. Maghari A, Forootan KS, Fathi M, Manafi A. Free transfer of expanded parascapular, latissimus dorsi, and expander “capsule” flap for coverage of large lower-extremity soft-tissue defect. Plast Reconstr Surg 2000;106(2):402-405.

\section{Legends}

Table: Summary of the patients - medical risk factors (arterial hypertension=1, obesity=2, tobacco abuse=3, alcohol abuse=4, diabetes mellitus: NIDDM=5, IDDM=6, thrombophilia=7,

This article is protected by copyright. All rights reserved. 
coagulative events=8(e.g. thromboembolism)); Defect size (in $\mathrm{cm}^{2}$ ); AVL (arterio-venous loop); Vessel for anastomosis (ATA=anterior tibial artery, ATP=posterior tibial artery; $\mathrm{AF}=$ femoral artery in the adductor canal); Postoperative complications (Major=requiring resurgery; Minor=conservative treatment; DS=donor-site; RS=recipient-site).

Figure 1: Anatomic scheme of the flap design.

Figure 2a-c: Large leg defect with exposed femur cement spacer. (b,c) Reconstructive result using the parascapular flap* to cover the cement spacer in order to facilitate surgical access to the femur for secondary osteosynthesis and the latissimus dorsi flap** to cover the knee (monitor skin paddle of the latissimus dorsi muscle flap***).

Figure 3a-c: Reconstructive result of the patient in Case 1 after 16 months.

Figure 4a-d: (a) Lateral view of a large leg defect. (b) Medial view (arterio-venous loop to the femoral vessels*). (c,d) Reconstructive result using the parascapular flap* to cover the arteriovenous loop and the latissimus dorsi flap** to cover the tibia (monitor skin paddle of the latissimus dorsi muscle flap***).

Figure 5a-e: Reconstructive result and donor-site appearance after split-thickness skin grafting of the patient in Case 2 after 14 months.

This article is protected by copyright. All rights reserved. 


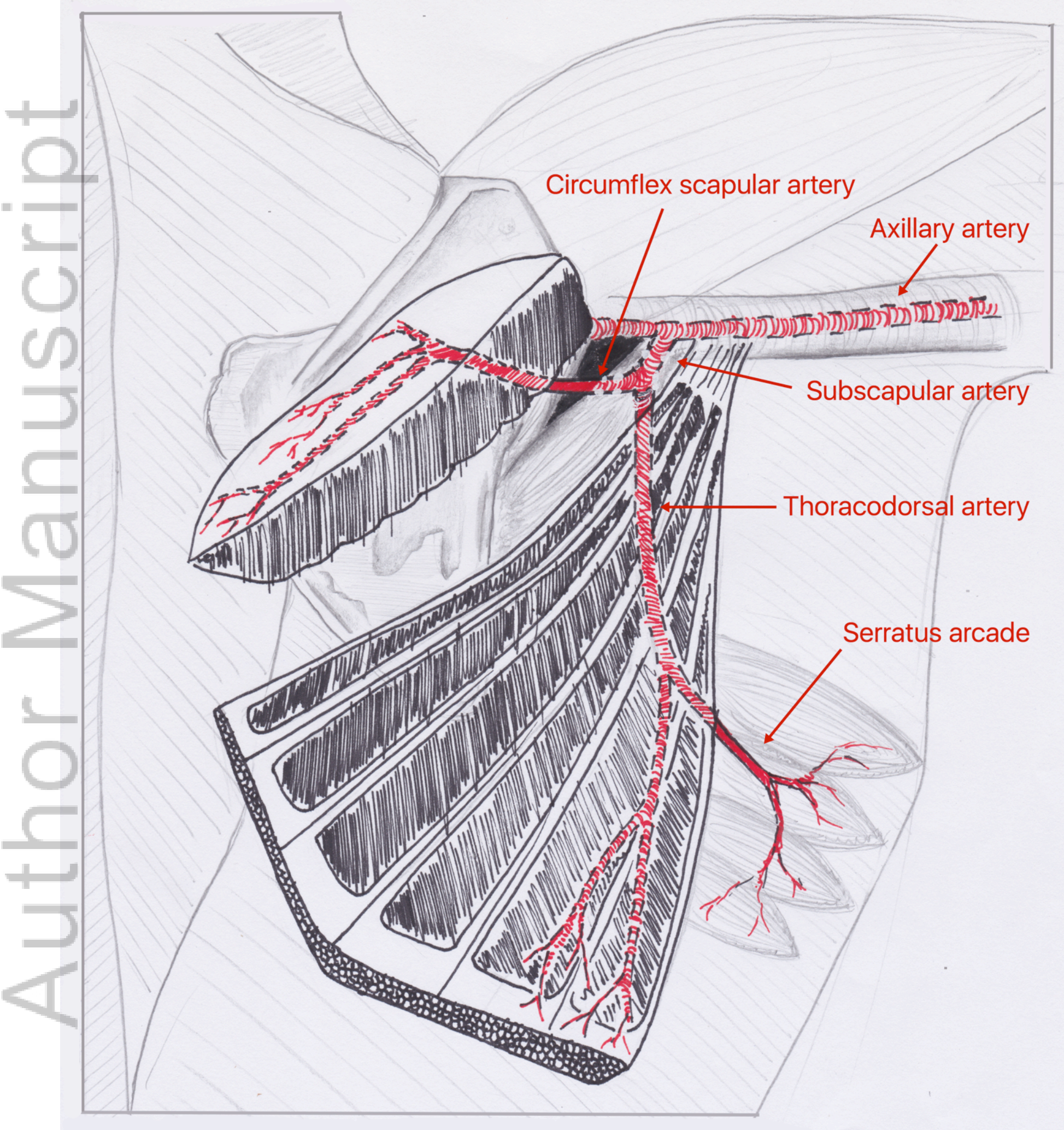

micr-17-0459-File002.tif

This article is protected by copyright. All rights reserved. 

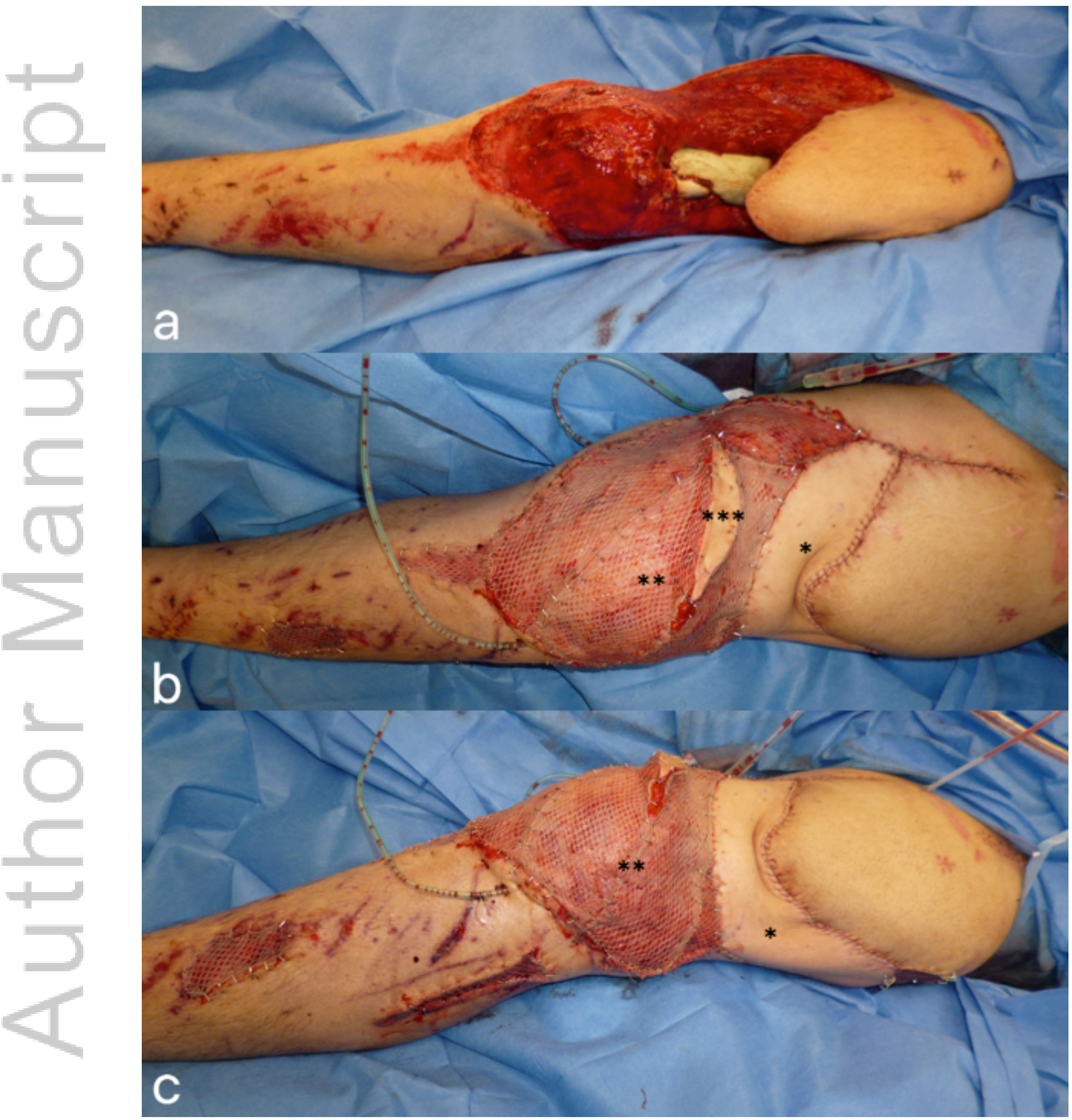

micr-17-0459-File003.tif

This article is protected by copyright. All rights reserved. 


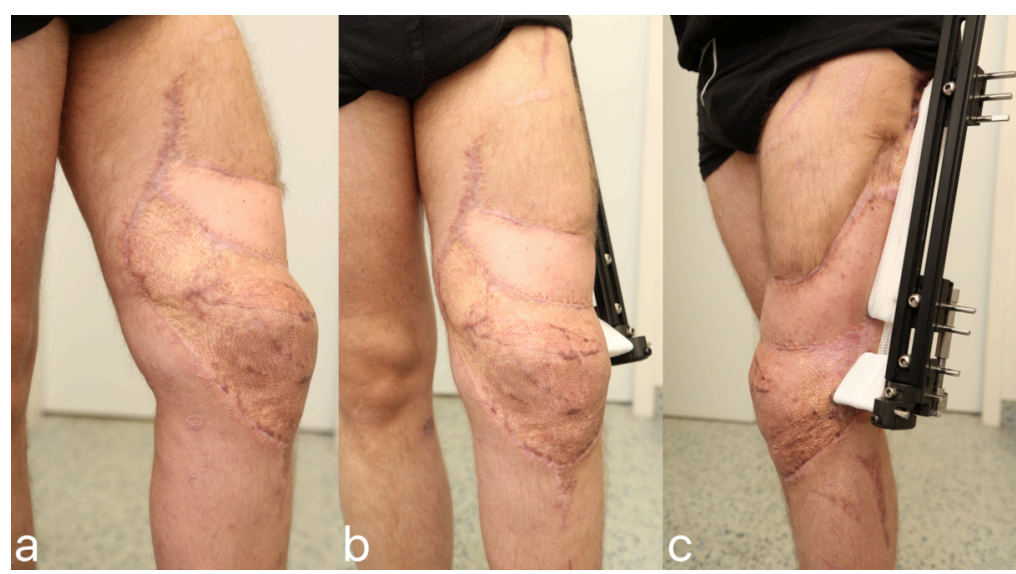

micr-17-0459-File004.tif

This article is protected by copyright. All rights reserved. 

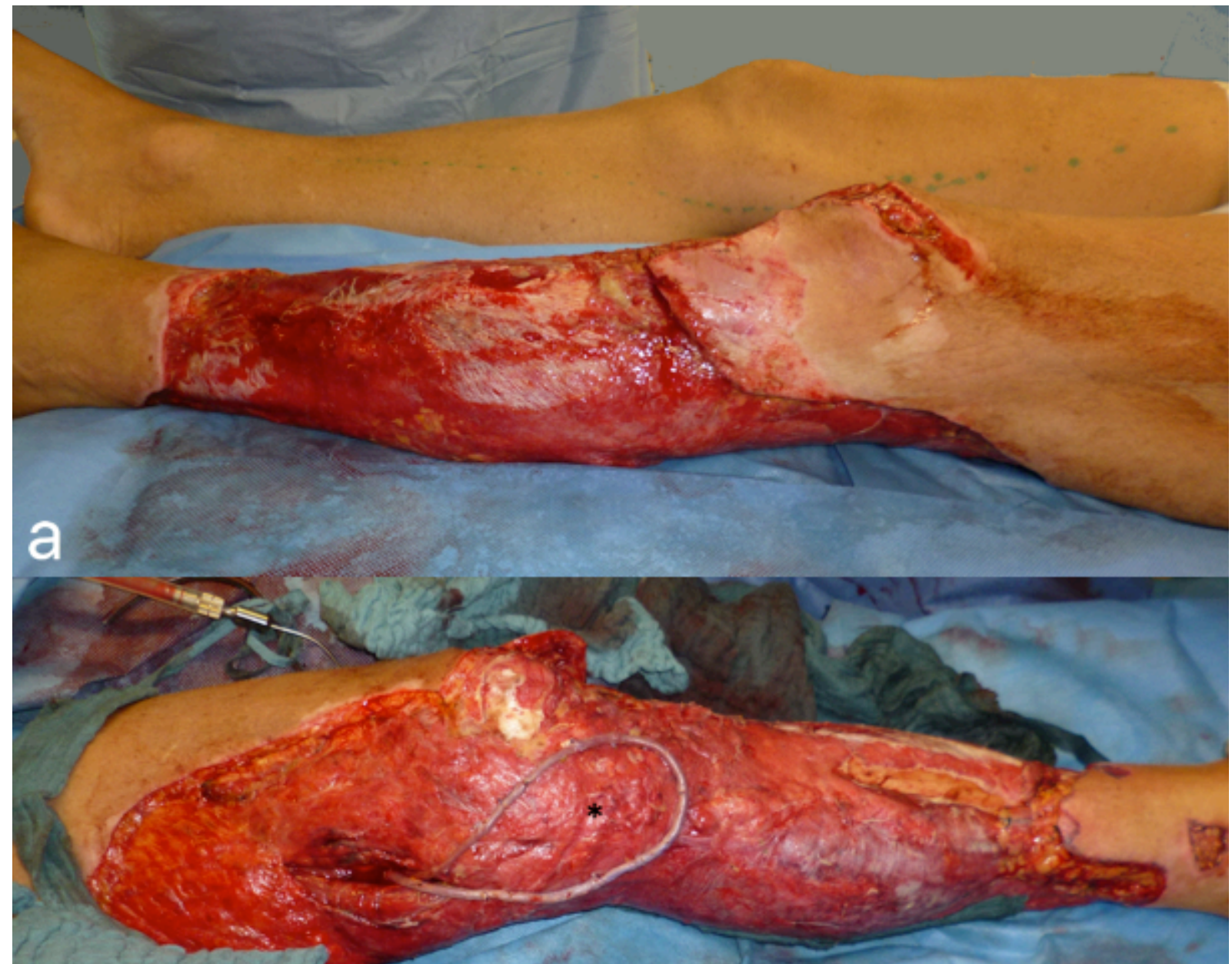

\section{b}
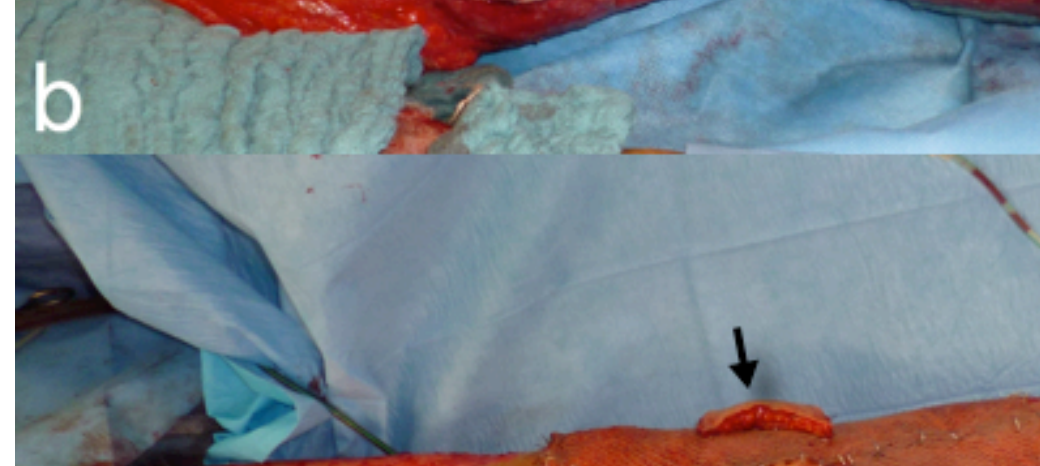


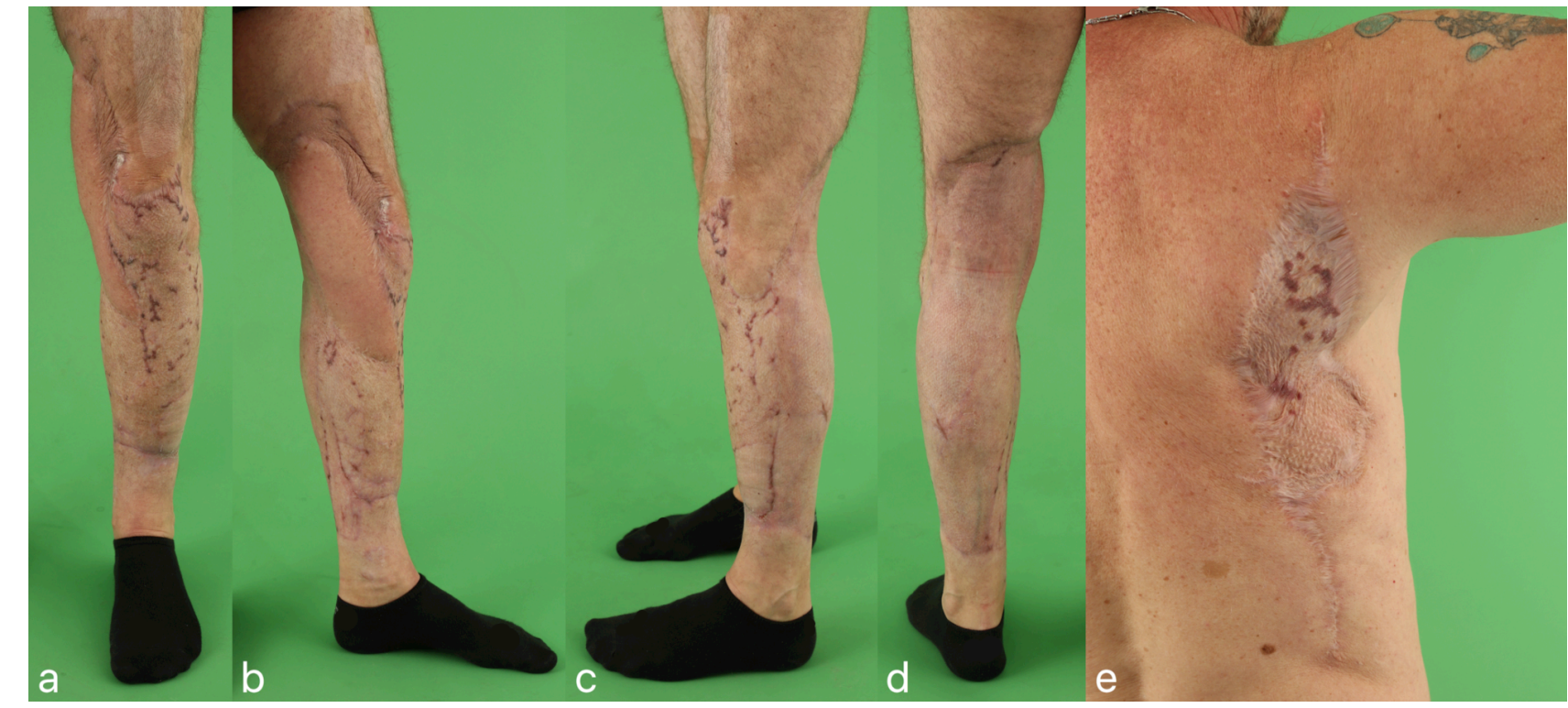

micr-17-0459-File006.tif

This article is protected by copyright. All rights reserved. 


\begin{tabular}{|c|c|c|c|c|c|c|c|c|c|c|c|c|c|c|}
\hline \multirow{2}{*}{ No. Age } & \multirow[t]{2}{*}{ Sex } & \multirow{2}{*}{$\begin{array}{l}\text { Risk } \\
\text { factor }\end{array}$} & \multirow{2}{*}{$\begin{array}{l}\text { Defect } \\
\text { cause }\end{array}$} & \multirow{2}{*}{$\begin{array}{l}\text { Defect } \\
\text { Localization }\end{array}$} & \multirow{2}{*}{$\begin{array}{l}\text { Defect } \\
\text { type }\end{array}$} & \multirow{2}{*}{$\begin{array}{l}\text { Defect } \\
\text { size }\end{array}$} & \multirow[t]{2}{*}{ AVL } & \multirow[t]{2}{*}{ Vessel } & \multirow{2}{*}{$\begin{array}{l}\text { Osteo- } \\
\text { synthesis }\end{array}$} & \multicolumn{2}{|c|}{ Postoperative complications } & \multirow{2}{*}{$\begin{array}{l}\text { Flap } \\
\text { survival }\end{array}$} & \multirow{2}{*}{$\begin{array}{l}\text { Follow- } \\
\text { up (months) }\end{array}$} & \multirow[t]{2}{*}{ Outcome } \\
\hline & & & & & & & & & & Major (DS / RS) & Minor (DS/RS) & & & \\
\hline 31 & $\mathrm{~m}$ & - & Infection & Knee, lower leg & circular & 512 & no & ATA & no & none/none & none/none & yes & 52.5 & able to walk \\
\hline & $\mathrm{f}$ & $1,2,4$ & Trauma & $\begin{array}{l}\text { Thigh, knee, } \\
\text { lower leg }\end{array}$ & circular & 2400 & no & ATP & no & none/none & none/none & yes & 46.9 & able to walk \\
\hline 64 & $\mathrm{f}$ & - & Trauma & Knee, lower leg & circular & 300 & no & ATP & no & $\begin{array}{l}\text { wound dehiscence/ } \\
\text { none }\end{array}$ & $\begin{array}{l}\text { none/ } \\
\text { wound dehiscence }\end{array}$ & yes & 45.6 & $\begin{array}{l}\text { able to walk } \\
\text { limping gait }\end{array}$ \\
\hline & $\mathrm{f}$ & - & Infection & $\begin{array}{l}\text { Thigh, knee, } \\
\text { lower leg }\end{array}$ & circular & 680 & no & ATP & no & none/none & none/none & yes & 33.6 & able to walk \\
\hline 68 & $\mathrm{f}$ & 1,8 & Trauma & Knee, lower leg & circular & 950 & no & $\mathrm{AF}$ & yes & none/none & none/none & yes & 33.6 & $\begin{array}{l}\text { Prosthesis } \\
\text { training }\end{array}$ \\
\hline 6 & $\mathrm{~m}$ & 2 & Trauma & $\begin{array}{l}\text { Thigh, knee, } \\
\text { lower leg }\end{array}$ & circular & 714 & no & $\mathrm{AF}$ & yes & $\begin{array}{l}\text { none/ } \\
\text { partial flap necrosis }\end{array}$ & none/none & yes & 26.5 & able to walk \\
\hline 45 & $\mathrm{f}$ & 3 & Trauma & Knee, lower leg & $\begin{array}{l}\text { semi- } \\
\text { circular }\end{array}$ & 1260 & no & AF & yes & seroma/none & none/none & yes & 29.4 & able to walk \\
\hline & $\mathrm{m}$ & 3 & Trauma & Knee & $\begin{array}{l}\text { semi- } \\
\text { circular }\end{array}$ & 1100 & no & $\mathrm{AF}$ & no & none/none & $\begin{array}{l}\text { seroma/ } \\
\text { wound dehiscence }\end{array}$ & yes & 26.0 & able to walk \\
\hline 58 & $\mathrm{f}$ & $1,2,6$ & Trauma & $\begin{array}{l}\text { Thigh, knee, } \\
\text { lower leg }\end{array}$ & $\begin{array}{l}\text { Semi- } \\
\text { circular }\end{array}$ & 750 & yes & $\mathrm{AF}$ & yes & $\begin{array}{l}\text { wound dehiscence/ } \\
\text { partial flap necrosis }\end{array}$ & none/none & yes & 21.9 & $\begin{array}{l}\text { Prosthesis } \\
\text { training }\end{array}$ \\
\hline & $\mathrm{m}$ & - & Infection & Knee, lower leg & circular & 385 & yes & $\mathrm{AF}$ & yes & $\begin{array}{l}\text { wound dehiscence/ } \\
\text { partial flap necrosis }\end{array}$ & none/none & yes & 19.0 & $\begin{array}{l}\text { able to walk/ } \\
\text { limping gait }\end{array}$ \\
\hline & $\mathrm{m}$ & 7,8 & Trauma & Knee, lower leg & $\begin{array}{l}\text { semi- } \\
\text { circular }\end{array}$ & 476 & no & $\mathrm{AF}$ & yes & hematoma/none & none/none & yes & 23.2 & able to walk \\
\hline 12 & $\mathrm{~m}$ & 5 & Trauma & Knee, lower leg & $\begin{array}{l}\text { semi- } \\
\text { circular }\end{array}$ & 273 & yes & $\mathrm{AF}$ & yes & none/none & none/none & yes & 17.0 & able to walk \\
\hline & $\mathrm{m}$ & 4 & Trauma & Knee, lower leg & $\begin{array}{l}\text { semi- } \\
\text { circular }\end{array}$ & 980 & no & $\mathrm{AF}$ & yes & $\begin{array}{l}\text { wound dehiscence/ } \\
\text { none }\end{array}$ & none/none & yes & 23.5 & $\begin{array}{l}\text { Waiting for } \\
\text { final surgery }\end{array}$ \\
\hline 14 & $\mathrm{f}$ & - & Trauma & Knee, lower leg & $\begin{array}{l}\text { semi- } \\
\text { circular }\end{array}$ & 350 & no & $\mathrm{AF}$ & no & none/none & $\begin{array}{l}\text { none/ } \\
\text { partial flap }\end{array}$ & yes & 12.4 & able to walk \\
\hline 15 & $\mathrm{~m}$ & - & Trauma & Knee, lower leg & $\begin{array}{l}\text { semi- } \\
\text { circular }\end{array}$ & 850 & no & $\mathrm{AF}$ & yes & none/none & $\begin{array}{l}\text { none/ } \\
\text { partial flap }\end{array}$ & yes & 6.0 & able to walk \\
\hline
\end{tabular}

This article is protected by copyright. All rights reserved. 
Table: Summary of the patients - medical risk factors (arterial hypertension=1, obesity=2, tobacco abuse=3, alcohol abuse=4, diabetes mellitus: NIDDM=5, IDDM=6, thrombophilia=7, coagulative events=8 (e.g. thromboembolism)); Defect size (in $\mathrm{cm}^{2}$ ); AVL (arterio-venous loop); Vessel for anastomosis (ATA=anterior tibial artery, ATP=posterior tibial artery; AF=femoral artery in the adductor canal); Postoperative complications (Major=requiring re-surgery; Minor=conservative treatment; DS=donor-site; RS=recipient-site). 